\title{
Management of traffic accident related ulnar artery injury
}

\author{
Hamit Serdar Başbuğ (iD, Kanat Özışık (iD) \\ Department of Cardiovascular Surgery, Kafkas University Faculty of Medicine, Kars, Turkey
}

Received: November 19, 2016 Accepted: May 21, 2018 Published online: April 24, 2019

Penetrating brachial vascular injuries constitute $50 \%$ of all penetrating wounds. ${ }^{[1]}$ The majority of penetrating injuries are caused by the stab (57\%), gunshots (29\%), and other sharp objects (7\%). The remaining $6 \%$ represents other injuries from road traffic accidents, gunshots injuries, or dog bites. ${ }^{[2]}$ In this report, we present a rare case of a traffic accident in which the wrist of the driver was cut, the ulnar artery was totally disrupted and repaired by the interposition of an autologous vein graft.

A 41-year-old male truck driver was referred to the emergency clinic after a road traffic accident injury with a massive open wound on his right wrist. There was massive bleeding from the wrist region with an extensive dermal tissue loss and tendon damage inside the wound. The ulnar artery was totally cut. He was conscious with a blood pressure of $95 / 55 \mathrm{mmHg}$ and a heart rate of $92 \mathrm{bpm}$. Palpation of the peripheral pulses revealed total pulse deficit on the right radial and ulnar arteries. Color Doppler ultrasound showed triphasic patterns in the axillary artery, brachial artery, and radial and ulnar arteries proximal to the level to trauma. The patient was diagnosed with a total disruption of the ulnar artery and an intimal damage of the radial artery.

A written informed consent was obtained from the patient and he was taken to the operating room. Under general anesthesia, the right wrist was explored through a longitudinal skin incision inside the wound. The disrupted ulnar artery edges were reached and were trimmed to be anastomosed. However, the ulnar artery was spasmodic without bleeding. A Fogarty catheter was advanced into the artery proximally. 5,000 IU unfractionated heparin was given intravenously. Massive thrombus was withdrawn from the ulnar and brachial artery. Proximal and distal bulldog clamps were placed to expose the precise arterial ends for anastomosis and to secure the artery from bleeding. A 5-cm long great saphenous vein (GSV) segment was harvested and interposed between the free edges of the ulnar artery. Thus, the ulnar artery was repaired with a GSV graft (Figure 1). As the arterial tissue loss was extensive, end-to-end anastomosis was unable to be done. Polypropylene No. $7 / 0$ with an $8-\mathrm{mm}$ needle was used as the suture material. Bulldog clamps were, then, removed and the arterial deairing was performed. There was no need for intraoperative blood product transfusion. Radial artery remained unoperated, as it had good collateral circulation from the palmar arch. Impaired tendons were repaired by the orthopedics. Gentamicin (160 mg/day), cefazolin (1500 mg/day), metronidazole (1500 mg/day), and acetylsalicylic acid (150 mg/day)

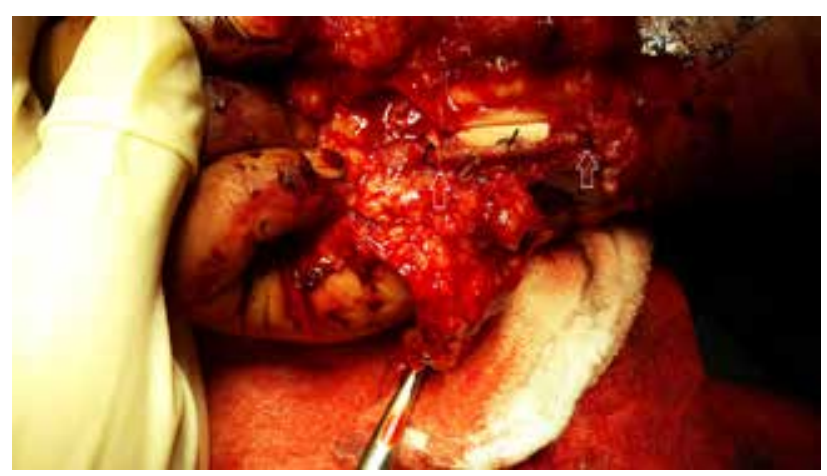

Figure 1. The left arrow showing distal anastomosis and the right arrow showing proximal anastomosis of the great saphenous vein graft interposing the disrupted ulnar artery.

Corresponding author: Hamit Serdar Başbuğ, MD. Kafkas Üniversitesi Tıp Fakültesi Kalp ve Damar Cerrahisi Anabilim Dal, 36100 Kars, Turkey.

Tel: +90 474 - 2251190 e-mail: s_basbug@hotmail.com

\section{Citation:}

Başbuğ HS, Özışık K. Management of traffic accident related ulnar artery injury. Cardiovasc Surg Int 2017;4(2):34-35. 
were prescribed during the postoperative period. The patient was discharged on the postoperative fifth day with intact distal ulnar and radial pulses and with no motor deficit.

In conclusion, traffic accident-related brachial injuries are uncommon, but potentially fatal. An amputation risk of the hand is always present. ${ }^{[2]}$ Vehicle road accidents may cause severe injuries to the vascular structures of the arm, neck, or even the face. The graft interposition is the most preferred type of reconstruction, if there is a gross vascular segmental loss. The great saphenous vein is widely used as an autologous vein graft for these arterial injuries. ${ }^{[3]}$

\section{Declaration of conflicting interests}

The authors declared no conflicts of interest with respect to the authorship and/or publication of this article.

\section{Funding}

The authors received no financial support for the research and/or authorship of this article.

\section{REFERENCES}

1. Van Waes OJ, Navsaria PH, Verschuren RC, Vroon LC, Van Lieshout EM, Halm JA, et al. Management of penetrating injuries of the upper extremities. Ulus Travma Acil Cerrahi Derg 2013;19:405-10.

2. Zellweger R, Hess F, Nicol A, Omoshoro-Jones J, Kahn D, Navsaria P. An analysis of 124 surgically managed brachial artery injuries. Am J Surg 2004;188:240-5.

3. Dragas M, Davidovic L, Kostic D, Markovic M, Pejkic $\mathrm{S}$, Ille $\mathrm{T}$, et al. Upper extremity arterial injuries: factors influencing treatment outcome. Injury 2009;40:815-9. 